\title{
Análise da Utilização do Cartão BNDES nas Regiões Brasileiras no Período 2004-2014
}

\author{
Mauro Thury de Vieira Sá \\ Universidade Federal do Amazonas - Manaus - Amazonas - Brasil \\ ORCID: https://orcid.org/0000-0002-8127-4091 \\ Diogo Del Fiori \\ Universidade Federal do Amazonas - Manaus - Amazonas - Brasil \\ ORCID: https://orcid.org/0000-0002-1315-1233 \\ Petrick Kristofer Andrade da Costa \\ Associação Voluntários para o Serviço Internacional - Brasília - Distrito Federal - \\ Brasil \\ ORCID: https://orcid.org/0000-0002-7980-1315
}

\section{Resumo}

O trabalho objetiva analisar aspectos da destinação dos valores contratados do cartão BNDES. Intenta-se verificar o viés setorial das operações contratadas via cartão BNDES por unidade da Federação (UF), bem como analisar a distribuição desses recursos nas UFs comparativamente à da população e de outras variáveis econômicas. Aplicando-se o quociente locacional (QL), para o ano de 2004, os estados com o maior número de setores (cinco ou mais) com QL>1 na região sudeste foram São Paulo, Rio de Janeiro Minas Gerais. No Sul, o Rio Grande do Sul, no Nordeste a Bahia. No Centro Oeste, o Distrito Federal e o Mato Grosso. Para o ano de 2014, no sudeste o estado de São Paulo, Rio de Janeiro, Minas Gerais e o Espírito Santo. No Sul, Rio Grande do Sul e Santa Catarina. No Nordeste, Alagoas, Sergipe, Bahia, Ceará, Paraíba, Pernambuco e o Rio Grande do Norte. No Centro Oeste, o Distrito Federal, Goiás, Mato Grosso e Mato Grosso do Sul. Para o Norte, Acre, Amapá, Amazonas, Pará e Tocantins. Verificou-se, por intermédio da Curva de Lorenz, uma alteração do quadro de utilização do cartão, que em 2004 se concentrava nas regiões Sul e Sudeste, que juntamente com o Centro-Oeste, apresentaram especialização em setores, no qual todas as unidades federativas dessas regiões também apresentaram. Em 2014, todas as regiões apresentam especialização de determinada atividade em todas as suas unidades federativas, além da diminuição da representatividade do Sudeste na utilização do cartão, com o Nordeste ganhando uma fatia maior no valor total das operações.

Palavras-chave: Empresas. Crédito. BNDES. Quociente Locacional. 


\title{
Analysis of the use of the BNDES card in Brazilian Regions in the period 2004-2014
}

\begin{abstract}
The work aims to analyze aspects of the destination of the values contracted from the BNDES card. It is intended to verify the sectoral bias of the operations contracted via BNDES card per unit of the Federation (UF), as well as to analyze the distribution of these resources in the UFs compared to that of the population and other economic variables. Applying the locational quotient (QL), for the year 2004, the states with the largest number of sectors (five or more) with QL>1 in the southeastern region were São Paulo, Rio de Janeiro Minas Gerais. In the South, Rio Grande do Sul, in the Northeast Bahia. In the Midwest, the Federal District and Mato Grosso. For 2014, in the southeast, the state of São Paulo, Rio de Janeiro, Minas Gerais and Espírito Santo. In the South, Rio Grande do Sul and Santa Catarina. In the Northeast, Alagoas, Sergipe, Bahia, Ceará, Paraíba, Pernambuco and Rio Grande do Norte. In the Midwest, the Federal District, Goiás, Mato Grosso and Mato Grosso do Sul. To the North, Acre, Amapá, Amazonas, Pará and Tocantins. There was, through the Lorenz Curve, a change in the use of the card, which in 2004 was concentrated in the South and Southeast regions, which together with the Midwest, had specialization in sectors, in which all the federative units of these regions also featured. In 2014, all regions showed specialization in a given activity in all their federal units, in addition to the decrease in the representativeness of the Southeast in the use of the card, with the Northeast gaining a larger share in the total value of operations.
\end{abstract}

Keywords: Companies. Credit. BNDES. Locational Quotient.

\section{Análisis del uso de la Tarjeta BNDES en las Regiones Brasileñas en el Período 2004-2014}

\section{Resumen}

El trabajo tiene como objetivo analizar aspectos del destino de los valores contratados de la tarjeta BNDES. Se pretende verificar el sesgo sectorial de las operaciones contratadas vía tarjeta BNDES por unidad de la Federación (UF), así como analizar la distribución de estos recursos en las UF en comparación con la de la población y otras variables económicas. Aplicando el cociente de ubicación (CV), para el año 2004, los estados con mayor número de sectores (cinco o más) con CV> 1 en la región sureste fueron São Paulo, Río de Janeiro Minas Gerais. En el sur, Rio Grande do Sul, en el noreste de Bahía. En el Medio Oeste, el Distrito Federal y Mato Grosso. Para 2014, en el sureste, el estado de São Paulo, Río de Janeiro, Minas Gerais y Espírito Santo. En el sur, Rio Grande do Sul y Santa Catarina. En el Nordeste, Alagoas, Sergipe, Bahia, Ceará, Paraíba, Pernambuco y Rio Grande do Norte. En el Medio Oeste, el Distrito Federal, Goiás, Mato Grosso y Mato Grosso do Sul. Al Norte, Acre, Amapá, Amazonas, Pará y Tocantins. Hubo, a través de la Curva de Lorenz, un cambio en el uso de la tarjeta, que en 2004 se concentró en las regiones Sur y Sudeste, que junto con el Medio Oeste, tenían especialización en sectores, en los que todas las unidades federativas de estas regiones también presentado. En 2014, todas las regiones mostraron especialización en una determinada actividad en todas sus unidades federales, además de la disminución en la representatividad del Sudeste en el uso de la tarjeta, con el Nordeste ganando una mayor participación en el valor total de las operaciones.

Palabra clave: Empresas. Crédito. BNDES. Cociente de ubicación. 


\section{Introdução}

Essencial para a economia nacional, as micro, pequenas e médias empresas (MPME), enfrentam diversos desafios para ultrapassar as dificuldades de acesso ao crédito. Segundo Stiglitz e Weiss e Stiglitz (1981), o acesso ao crédito é uma das principais ferramentas ao desenvolvimento econômico de uma nação, já que sem esses recursos, as empresas acabam por ter a sua produtividade e capacidade de investimento reduzidas, afetando a geração de emprego e de renda, contribuindo para o aumento nas taxas de mortalidade das MPME.

Observada a patente necessidade e o valor social de se expandir o acesso ao crédito das micro, pequenas e médias empresas, soluções são buscadas pela maioria dos países. No Brasil, várias iniciativas vêm sendo delineadas para reduzir esse problema, entre elas às desenvolvidas pelo Banco Nacional do Desenvolvimento Econômico e Social (BNDES). comoo cartão BNDES, lançado em 2003, destinado para financiamento das micro e pequenas empresas (GALINARI et al., 2017).

Alguns estados acabam conseguindo mais financiamentos do que outros, seja por ter mais projetos para avaliação, mais empresários ou um Produto Interno Bruto (PIB) maior, então é necessário verificar quais estados acabam conseguindo mais financiamentos, em que setores esses financiamentos estão acontecendo e se está ocorrendo uma concentração dessas operações em determinada região. Além de também analisar as possíveis especializações produtivas que as unidades federativas podem apresentar, pois um alto valor de operações contratadas em determinado setor, pode apontar para um crescimento econômico da atividade, naquele espaço. A necessidade de se verificar a forma que o dinheiro do BNDES está sendo empregado é uma das justificativas de se realizar esse estudo, além de se verificar o comportamento dessas operações no país, caracterizando de forma nacional e por parte das unidades federativas a utilização do cartão BNDES.

Desta maneira, neste artigo os objetivos são estudar como os valores contratados do cartão BNDES são destinados, buscando-se averiguar se há nas operações contratadas do cartão BNDES viés setorial por unidade da federação e estudar a distribuição desses recursos nas unidades da federação, por meio da aplicação da curva de Lorenz, comparando-se com a distribuição do tamanho da população, do Produto Interno Bruto (PIB) ee da quantidade de Micro, Pequenas e Médias Empresas (MPMEs) para os anos de 2004 e 2014. O cálculo do coeficiente locacional $(\mathrm{QL})$ terá por meta averiguar para quais setores e unidades da federação os recursos do cartão BNDES estão sendo destinados em 2004 e 2014, assim sendo, os resultados desses coeficientes permitirão dar embasamento para explicar os resultados da curva de Lorenz para o período proposto de estudo, mostrando quais setores foram os responsáveis nas regiões Norte, Nordeste e Centro-Oeste pelo aumento da demanda por recursos do cartão BNDES, impactando na desconcentração desses recursos na região Sudeste e Sul se comparado osanos de 2004 e 2014. 


\section{Referencial Teórico}

\subsection{Desigualdades Regionais}

Para Barros (2011) as desigualdades regionais do Brasil, nascem das disparidades de capital humano, já que no processo de formação histórica do país, a colonização gerou desigualdades na disponibilidade de capital humano, no qual as regiões Sul e Sudeste, recebiam imigrantes que detinham um conhecimento mais apurado, sendo que o mesmo acabava não ocorrendo no Nordeste, que recebia imigrantes com um conhecimento menos apurado. Se pode complementar, que essas desigualdades atingem níveis ainda maiores devido a disparidade entre as rendas dos indivíduos educados e não educados é demasiadamente alta, devido à má distribuição de renda no país.

Dow (1982, apud Dutra et al 2015), afirma que o sistema financeiro das regiões e as condições determinadas pelo lado real da economia acabariam ocasionando formas de desenvolvimento regionais desiguais, por duas situações. A primeira seria referente aos bancos privados nacionais, que realizariam poucos empréstimos em regiões pouco desenvolvidas, já que as condições não seriam às melhores, além de poder de controle sobre as filiais. A segunda seria devia a preferência pela liquidez, bancos regionais, poderiam querer manter um alto nível de reservas, e dificultar os empréstimos a regiões menos desenvolvidas.

A partir de 2000, houve uma maior participação das três regiões de menor desenvolvimento (Norte, Nordeste e Centro-Oeste) do país na composição do PIB nacional, em comparação à década de 90 , apontando para o fortalecimento para o encontro dessas rendas regionais. O governo federal teve papel nesse processo, por meio da desconstrução produtiva em curso, todavia, com um enfraquecimento dos instrumentos clássicos de política regional (fundos constitucionais e fiscais). $O$ principal agente do governo para esse desenvolvimento regional, foi o BNDES (MONTEIRO NETO, 2014).

\subsection{Financiamento}

Segundo Zica e Martins (2008), o acesso ao crédito é uma das mais importantes ferramentas para o desenvolvimento econômico de um país. Sem a obtenção de recursos, as empresas diminuem sua capacidade produtiva e de investimento, reduzem os patamares de faturamento e de geração de emprego e renda, o que acaba contribuindo para o aumento da mortalidade das micro e pequenas empresas. A mesma dificuldade é percebida pelas instituições financeiras, que não conseguem reduzir o risco para liberarem o financiamento em detrimento da falta de garantias e de informações confiáveis sobre o negócio.

Em sua obra "A teoria do desenvolvimento econômico", Schumpeter (1985), argumenta que o empresário não necessita de crédito para produzir, se for no sentindo de lhe dar poder de compra, e realizar suas novas transformações e tornarse empresário; mas quando não o possuísse deveria então se comprometer junto às instituições financeiras. 
Se por acaso ele não o possuir... deve toma-lo emprestado. Se ele não conseguir, então obviamente não pode tornar-se empresário...o que ele quer primeiro é crédito. Antes de requerer qualquer espécie de bens, requer poder de compra. É o devedor típico na sociedade capitalista.

Segundo Shumpeter (1962) apud Souza (1997, p. 131), quando tange a questão dos recursos, destaca-se que,

\begin{abstract}
Como o empresário não é necessariamente, o proprietário dos meios de produção que pode estar disseminado entre uma miríade de pequenos acionistas, nem possui recursos próprios suficientes para a realização do investimento e adotar novas combinações, o crédito bancário apresentase como uma necessidade real, para que esse agente virtual se torne efetivamente empresário.
\end{abstract}

Além de Shumpeter, outros teóricos argumentavam sobre a questão da importância do crédito para o empresário. Segundo Steindl (1945 apud GUERRA, TEIXEIRA, 2010, p.131), a dificuldade em ter acesso ao crédito, afetaria a capacidade de endividamento das firmas pequenas, já que isso inviabilizaria a passagem da firma da categoria de pequena para grande.

Dentre os instrumentos de política industrial, o uso dos mecanismos financeiros públicos é certamente dos mais importantes. Por meio do direcionamento de crédito para setores, regiões ou grupos sociais específicos, da criação de fundos garantidores, de fundos orçamentários e da ação de bancos de desenvolvimento, os governos procuram garantir recursos financeiros em condições adequadas aos investimentos necessários (Toni, 2015).

\title{
2.3 BNDES
}

Os Bancos Públicos de Desenvolvimento (BPDs) nascem com o objetivo de corrigir falhas de mercado do sistema financeiro, além de apoiar setores estratégicos do país. Não existem apenas um conceito para as BPSs, todavia, se costuma usar a definida pela Organização das Nações Unidas (ONU) "BPDs são instituições financeira instituídas pelo governo para incentivar o desenvolvimento econômico; na maioria das vezes, considera objetivos de desenvolvimento social e de integração social, provendo ou facilitando o financiamento de longo prazo para projetos que gerem externalidades positivas (FERRAZ, ALÉM, MADEIRA, 2013; ALMEIDA, 2017).

Segundo Almeida (2017) as falhas na oferta de crédito podem ser preenchidas por bancos públicos de desenvolvimento, caso duas dessas condições se verificarem. Primeiro, se os setores, empresas ou projetos-alvo das intervenções estão sub atendidos pelas fontes de financiamento privado. Por exemplo, os bancos comerciais não têm acesso suficiente a funding de longo prazo para infraestrutura ou a empresa estrategicamente importante alcançou o seu limite de crédito junto aos bancos comerciais. Segundo, se, de fato, a intermediação pública no setor privado for a solução mais efetiva para preencher esta demanda e gerar um benefício social, econômico ou ambiental que supere o investimento por um indicador de retorno aceitável. As instituições financeiras podem não ofertar financiamento suficiente para certos setores, empresas ou projetos, por três razões: 
i) porque têm pouco apetite para certos riscos; ii) porque teriam custos transacionais altos; ou iii) porque não têm capacidade financeira para oferecê-lo (por exemplo, por falta de acesso a funding ou por alcançar seu limite de crédito).

A partir dessa perspectiva, promoveu-se a criação de bancos nacionais de desenvolvimento (BND) em diferentes regiões do mundo entre os quais se destaca o caso brasileiro do Banco Nacional do Desenvolvimento Econômico - BNDE, criado em 1952. As referidas instituições deveriam canalizar recursos internacionais e nacionais, em longo prazo, para promover a expansão da infraestrutura e da indústria moderna. Para isso, deveriam contar com corpo funcional capaz de avaliar projetos com base em técnicas mais avançadas de análise e atuar conforme as melhores práticas de contratação financeira. Os bancos de desenvolvimento seriam, assim, peças relevantes nos mecanismos de direcionamento de crédito a partir dos Estados Nacionais comandariam o financiamento em longo prazo de seus programas nacionais de desenvolvimento (TORRES FILHO; COSTA, 2012).

O BNDES foi criado com o objetivo de suprir um dos principais obstáculos ao desenvolvimento do país: a falta de financiamento de longo prazo para investimento em infraestrutura e projetos industriais. Atualmente, é uma empresa pública de direito privado de âmbito federal, possui capital próprio e está à supervisão do Ministro de Estado do Desenvolvimento, Indústria e Comércio Exterior. Seus objetivos, de acordo com o estatuto Social do BNDES (arts $3^{\circ}$ e $4^{\circ}$ ), são os seguintes:

\begin{abstract}
Art. $3^{\circ}$ O BNDES é o principal instrumento de execução da política de Investimento do Governo Federal e tem por objetivo primordial apoiar programas, projetos, obras e serviços que se relacionem com 0 desenvolvimento econômico e social do País.

Art. $4^{\circ} \mathrm{O}$ BNDES exercitará suas atividades, visando a estimular a iniciativa privada, sem prejuízo de apoio a empreendimentos de interesse nacional a cargo do setor público.
\end{abstract}

No período de 1952 e 1960, a infraestrutura recebeu 69,4\% das aprovações do BNDES, o que equivale a dois terços do total. Já a participação da indústria nesse período foi de $28,4 \%$. A participação da agropecuária foi muito baixa e do setor de serviços e comércio foi de apenas 2,2\%. Essa estruturação dos empréstimos estava em linha com a meta de dar elevado nível de suporte para a modernização da infraestrutura nacional e para a construção por intermédio da criação do BNDES. Dando abertura aos financiamentos no período de 1952-1960 à infraestrutura, notase que os mais importantes foram os setores de energia elétrica (com $26,8 \%$ de participação da totalidade nos financiamentos) e infraestrutura ferroviária (com 41,4\% de participação nos financiamentos) foram os na primeira década da presença do BNDES os mais importantes. Em 1952, deu-se inicio ao primeiro projeto financiado pelo BNDES, que foi a Estrada de Ferro Central do Brasil, mostrando neste contexto como a infraestrutura das ferroviárias era imprescindível (BARBOZA; FURTADO; GABRIELLI,2018). 
A partir da década de 1960, o BNDES alterou suas políticas e começou a ser o banco da indústria nacional, mais especificamente da indústria de base no Brasil, por causa das inúmeras ações de industrialização por substituição de importações (ISI) Com esta política, alcançaram-se 70,6\% na década de 1960 a participação nas aprovações do Banco a indústria, com pouca importância da participação dos serviços e comércio (4,1\%), com queda para $25,2 \%$ na participação da infraestrutura. A agropecuária teve $0 \%$ de participação. Não houve grande alteração da composição setorial do BNDES nos anos de 1970, com a liderança dos financiamentos estando atrelada à indústria (participação de $67,4 \%$ ), enquanto a segunda colocação ficou para a infraestrutura (participação de 27,0\%). Entretanto, houve uma ligeira alteração na estruturação dos segmentos industriais no que tange à década anterior, com diminuição de participação dos insumos básicos (sobremaneira pela diminuição na participação da siderurgia, que foi de $41,8 \%$ para 18,3\%) e elevação de participação de outros setores da indústria ( produtos alimentares, calçados, têxteis, entre outros) cuja soma ocasionou uma elevação de 7,9\% de participação para 16,5\%. Também houve mudanças na segmentação dos financiamentos destinados a infraestrutura na década de 1970. Destacam-se o crescimento do apoio à infraestrutura de transporte, predominantemente ferroviário (de 3,0\% para 7,1\%) e a diminuição de participação dos empréstimos para energia elétrica (de 16,1\% para $11,4 \%$ da totalidade dos empréstimos). Os segmentos da agropecuária, serviços e comércio e serviços continuaram recebendo baixo suporte (BARBOZA; FURTADO; GABRIELLI,2018).

Na década de 1980, foi mantida a participação setorial nas políticas de suporte do BNDES, mantendo-se a mesma prioridade da década anterior, mas existe uma nítida diversificação nesse suporte. No que tange aos anos de 1970, existiu um aumento aproximado de $6 \%$ no apoio ao setor de serviços e comércio (de 5,6\% para $11,1 \%$ ) e de forma aproximada uma diminuição de $10 \%$ na participação da indústria (que foi de $67,4 \%$ para $57,4 \%$ ). Da mesma maneira, houve crescimento do apoio à agropecuária, de $0 \%$ para $1,5 \%$. O crescimento no financiamento aos segmentos de serviço, comércio e agropecuário nos anos 1980 mostra o começo de um contexto em que esses segmentos começam a obter uma relativa relevância no apoio do BNDES(BARBOZA;FURTADO; GABRIELLI,2018).

No que se refere ao setor agropecuário, os anos de 1990 se destaca pelo elevado crescimento da sua participação, para $11 \%$ do suporte do BNDES, o que equivale a um crescimento de quase $10 \%$ se comparado à década anterior. Esse crescimento fez com que a soma da participação dos segmentos de serviços, comércio e agropecuário - historicamente com baixa importância no suporte do Banco - fosse nos anos de 1970 de cerca de 6\%, para aproximadamente 13\%, na década de 1980, alcançando 19\% na década de 1990. A contrapartida desse crescimento foi de novo a queda do segmento da indústria, que continuou tendo relevância, com representatividade de aproximadamente metade (48\%) do apoio do Banco. Ficou constante próximo a $32,8 \%$ dos financiamentos a participação da infraestrutura (BARBOZA; FURTADO; GABRIELLI, 2018). 
Entre os anos 2001-2010, foram estáveis as características setoriais no que tange aos dez anos anteriores. A mudança foi baixa, com: (i) pequena elevação do segmento de infraestrutura (cuja participação foi de 32,8\% na década de 1990 para 33,6\% nos anos 2000); (ii) pequeno elevação do segmento de serviços e comércio (de $8,3 \%$ para 10,4\%); (iii) queda reduzida do segmento da agropecuário (de $11 \%$ para9,4); e (iv) pequena diminuição do segmento industrial (de 48\% para 46,6\%) (BARBOZA; FURTADO; GABRIELLI,2018).

Com relação ao crédito do BNDES, no que se refere à estruturação setorial, as informações mostram que os anos de 1991-2010 poderiam ser organizados em um período homogêneo único (BARBOZA; FURTADO; GABRIELLI,2018).

Recentemente, que engloba os anos de 2011 a 2017, nota-se uma alteração substancial na estruturação do apoio do Banco. Houve elevado crescimento da participação do setor de serviços e comércio, que vai do patamar de 10\%, nos anos 2000 , para $23,9 \%$, o que denota um aumento de aproximadamente14\%. Entre outras explicações, esse crescimento de participação se relaciona com: (i) aos mecanismos BNDES PSI e Cartão BNDES, que aumentaram substancialmente a ajuda ao segmento de serviços e de comércio; e (ii) haja vista que a classificação de inúmeras operações com a administração pública (como com os municípios e estados) ser realizada no segmento de serviços e de comércio.A indústria, por seu turno, tem queda de aproximadamente $18 \%$, passando a ter $28,8 \%$ da totalidade dos financiamentos do Banco. Os outros segmentos, infraestrutura e agropecuário tiveram um ligeiro crescimento de sua participação no que tange ao período anterior. Afirma-se que a indústria perde importância em virtude do crescimento da importância do segmento de serviços e de comércio, inserindo-se a relevância de operações com a administração pública (BARBOZA; FURTADO; GABRIELLI, 2018).

No debate econômico, as MPMEs costumam ser vistas como de ordem meramente social, o que acaba direcionando-as exclusivamente a políticas de geração de emprego e renda, desprezando o caráter sistêmico do ambiente econômico. É necessário que as MPMEs sejam compreendidas no âmbito das políticas industriais e de desenvolvimento, já que pela sua significância, são elas que conformam o ambiente econômico global do país, e ditam o ritmo da dinâmica como um todo. A questão do entrave ao desenvolvimento das MPMEs não é só uma questão social, mas também um entrave a aceleração do crescimento nacional (NOGUEIRA; ZUCOLOTO,2017).

Segundo Beck, Demirguc-kunt e Levine (2005), apesar de existir uma forte associação positiva entre o desenvolvimento das MPMEs e o crescimento econômico, não existe uma relação significativa entre essas duas variáveis, todavia, aponta que economias em crescimento estão propícias a terem um mercado de MPMEs bem-sucedidas. Um dos fatores que ajudaria tanto no crescimento econômico quanto no desenvolvimento das MPMEs, seria um ambiente de negócio favorável, incentivando a concorrência, facilitando as transações comerciais, além de informações sobre as barreiras de entrada e saída, direitos de propriedade e uma fiscalização eficiente dos contratos. 
A assimetria de informações entre bancos e gestores das empresas pode ser considerado como um dos obstáculos ao crescimento dessas firmas. Pode acontecer que por falta de informação, o crédito não possa ser concedido, ou seja liberado, todavia, os juros pagos serão maiores do que numa situação em que houvesse simetria de informações. Um outro fator seria a inexistência ou então o reduzido valor de garantias a serem dadas, o que de certa forma poderia inviabilizar empréstimos. Empresas estariam bem menos suscetíveis a enfrentarem esse tipo de situação, pois dispõe de mais recursos para evitar essa assimetria de informações e tendo maior capacidade de tomar empréstimos (PEZZI, 2005).

A realidade empresarial brasileira é eminentemente composta por MPMEs, que são as verdadeiras responsáveis pela geração de emprego no país. Assim, seu fomento é necessário e incentivável. Como apontaram Audretsch e Feldman (1999), as pequenas unidades nascentes são vistas como agentes de mudança, com papel crucial na inovação tecnológica, mas também impõem, sob a ótica tradicional, custos excessivos para a economia como resultado de escalas de produção ineficientes, implicando em baixa produtividade e baixos salários para seus trabalhadores. Para estes autores, as MPES nascentes têm em seus primeiros anos de existências muitas incertezas quanto à demanda de seus produtos. Eles apontam ainda que muito dos motivos que não permitem que tais empresas sobrevivam no longo prazo, tenham relação com a própria competência do empresário e de seus empregados.

Umas das formas mais simples para que as MPMEs tenham acesso ao crédito ofertado pelo BNDES, é por meio do cartão do próprio banco. Lançado em 2002, o produto é uma linha de crédito rotativo pré-aprovada apara a aquisição de produtos credenciados pelo banco, com taxas de juros reduzidas e prazos para pagamentos estendidos sem cobrança de anuidade. A ideia do cartão surgiu no início da década de 90, quando foi criado uma comissão de trabalho para estudar como o BNDES, poderia ajudar na redução do desemprego. Umas das sugestões desse grupo, foi a criação de um cartão direcionado às MPMEs, já que empresas de menor porte teriam um custo menor na geração de empregos. A ideia acabou não sendo analisa pela diretoria, voltando ao debate apenas em 2001, quando se elaborou uma proposta, voltando o cartão para a aquisição de bens de capital, sendo então aprovada pela diretoria (NOGUEIRA E ZUCOLOTO,2017; PAULA,2017).

Nogueira e Zucoloto (2017) colocam o cartão como um instrumento que auxilia no desenvolvimento produtivo do país, por ter juros subsidiados e ser submetido a regras mais simples do que outros programas de créditos governamentais normalmente impõem. Essa facilidade, acaba apoiando principalmente aquelas empresas que estão em regiões historicamente mais carentes do país, se mostrando um instrumento de redução da heterogeneidade regional. 


\section{Metodologia}

A metodologia aplicada a este trabalho, irá se utilizar da análise dos aspectos econômicos e demográficos do país, nos anos 2004 e 2014, bem como dos resultados obtidos por meio do quociente locacional. $O$ levantamento estatístico se baseou nos dados do IBGE e do BNDES.

As informações fornecidas pelo BNDES, servirão de base para a construção dos índices dos quocientes locacionais e se referem ao valor das operações contratadas do cartão BNDES nos setores produtivos das regiões Norte, Nordeste, Centro-Oeste, Sudeste e Sul entre 2004 e 2014.Dessa maneira, a partir dos índices de quociente locacional, e os dados econômicos e demográficos das regiões brasileiras, será obtido uma trajetória da utilização do cartão, e se verificar a evolução de um ano para o outro.

Os dados referentes a população foram obtidos em Estimativas de População, que se encontram no Sistema IBGE de Recuperação Automática (SIDRA) do Instituto Brasileiro de Geografia e Estatística (IBGE), produto interno bruto (PIB) no catálogo das contas regionais da biblioteca do IBGE, e número de Micro, Pequenas e Médias Empresas (MPMEs) em estatísticas do cadastro central de empresas (CEMPRE) tendo por base a definição do IBGE, que consiste em utilizar o número de empregados para definir o porte da empresa para o ano de 2004 e no cadastro central de empresas do SIDRA para o ano de 2014 eos valores das operações do cartão BNDES foram obtidos por meio de solicitação junto ao BNDES, não estando disponível para o domínio público. Esses dadosserão utilizados para a construção de um gráfico, baseando-se na curva de Lorenz, para medir o grau de desigualdade das variáveis nas regiões. Todas as variáveis estarão sobrepostas no mesmo gráfico para a melhor visualização das curvas.

Os setores econômicos utilizados para a análise, serão os da Classificação Nacional das Atividades Econômicas (CNAE), descrita no site da Receita Federal do Brasil. subclasses 2.2, sendo importante frisar que na análise, as atividades $L, M$ e $N$, estarão juntas como uma só atividade, denominadas, L-N. Na imagem abaixo estão as atividades econômicas segundo a CNAE, e a sua denominação. As atividades que serão analisadas serão de $A$ até $S$.

\subsection{Quociente Locacional}

O quociente locacional contrasta a participação percentual da variável base de uma região em um setor particular com a participação percentual das mesmas regiões no total do emprego nacional ou do estado (HADDAD,1989). Nesta pesquisa, o quociente locacional indicará a especialização das operações contratadas no cartão BNDES em um setor das regiões brasileiras, com a participação de todos os setores no total do Brasil.

Para Haddad (1989), o cálculo da fórmula do quociente locacional é a seguinte:

$$
Q L=\frac{\frac{E_{i j}}{E_{i s}}}{\frac{E_{o j}}{E_{o .}}}
$$


Onde: $E_{j}^{i}=$ Emprego do setor econômico $i$ na região $j_{\text {; }}$

$E_{i,}=$ Emprego no setor i de todas as regiões

$E_{. j}=$ Emprego em todos os setores da região J; e,

$E$ = Emprego em todos os setores de todos os setores de todas as regióes

Para Crocco et al.(2006), caso o setor econômico i na região j possua um QL maior que 1, esta região pode ser considerada especializada neste setor. Suzigan (2005) acrescenta ainda que, o QL indica a concentração relativa de uma determinada indústria, numa região comparativamente à participação dessa mesma indústria no espaço definido como base. Da mesma forma, Lima et al. (2006) afirmam que se o QL for $>1$ o estado é relativamente mais importante em termos do setor em questão do que em termos gerais de todos os setores.

O uso do QL para a variável selecionada permite caracterizar as operações do cartão BNDES em termos setoriais, captando se há viés dessas operações na direção de determinadas atividades da região (no caso, Estado ou DF) se comparado com a área de referência da qual faz parte. Desta forma, o QL compara os recursos contratados do cartão BNDES do estado com participação percentual do Brasil, região de referência. Assim, no presente estudo, o QL mostra quantas vezes o setor i é mais ou menos importante para a região j, o estado, vis-à-vis o país. Quando o QL possui valores maiores do que 1, a região j apresenta um maior direcionamento na contratação do recurso na modalidade de financiamento no ramo produtivo em questão do que pesam as operações desse setor no Brasil. Assim o setor receberá proporcionalmente mais recursos do cartão BNDES. O oposto vai acontecer quando o QL for menor do que 1.

Por exemplo, se um estado recebe $\mathrm{R} \$ 1000,00$ de recursos do cartão BNDES, e se um dado setor deste estado receber $\mathrm{R} \$ 300,00$, logo este setor detém $30 \%$ do total de recursos recebido pelo estado. Esse será o numerador da fórmula do QL. Entretanto, se no Brasil esse mesmo setor possui somente $5 \%$ (denominador da fórmula do $\mathrm{QL}$ ), observar-se-á que esse setor para a região é mais importante na absorção de recursos do cartão BNDES do que para o Brasil. Esta é a relativa imprescindibilidade que o QL mensura. Neste exemplo, QL das operações contratadas por firmas do setor neste estado seria igual a 6 . Logo o peso desse segmento econômico para o cartão BNDES na unidade da Federação em comento é maior do que para o Brasil como um todo.

Para a consecução do segundo objetivo específico, foram construídas, para os anos de 2004 e 2014, curvas de Lorenz para as seguintes variáveis: população, produto interno bruto (PIB), número de micro, pequenas e médias empresas e os recursos das operações do cartão BNDES. A curva de Lorenz expressa a distribuição relativa de determinada variável em dado domínio, que, no presente artigo é o conjunto das vinte e sete unidades da Federação (UFs). As porcentagens acumuladas das UFs brasileiras foram inseridas no eixo horizontal e a porcentagem do acumulado das variáveis no eixo vertical. A diagonal de $45^{\circ}$ desenhada a partir da origem indica perfeita igualdade da distribuição. O desvio desta curva a direita reflete divergência na distribuição. A extensão desse desvio é uma medida de concentração regional. 
Desse modo, procedeu-se uma análise de dominância de Lorenz para as quatro variáveis em cada ano, bem como entre as dos valores contratados via cartão BNDES para os dois anos. Ou seja, no caso de uma curva de Lorenz para os montantes do cartão BNDES abaixo da curva para outra variável, está indicado que as operações do BNDES em pauta se encontram mais desigualmente distribuídas. Se estiver acima, “dominando", a distribuição dos recursos do cartão BNDES é menos desigual.

O uso da curva de Lorenz pode ser visto na publicação Produto Interno Bruto dos Municípios, 2010-2013 do IBGE (2015). Nesta, foram apresentadas curvas para o $\mathrm{PIB}$, valor adicionado bruto da Agropecuária, da Indústria, da Administração, saúde e educação públicas e seguridade social (APU) e dos Serviços (exceto APU) com o fito de averiguar a ocorrência de concentração em termos dos municípios brasileiros. Mostrou, por exemplo, que o valor adicionado agropecuário é distribuído mais igualitariamente entre os municípios do que o da indústria.

Assim, para um país com desigualdades regionais, entre UFs, o procedimento adotado no presente artigo permite verificar se a modalidade de financiamento em análise está contribuindo para reduzi-las ou para ampliá-las. Ainda que não seja necessariamente sua finalidade, o cartão BNDES pode ter implicações regionais, assim como programas de governo, políticas públicas, mesmo de caráter horizontal, podem ter um rebatimento espacial heterogêneo.

Para a análise dos resultados, foi feita uma separação por ano, sendo explanado primeiramento sobre os resutados do quociente locacional para 2004, e logo em senguinte para 2014. A abordagem será por regiões, para poder haver uma melhor comparação das atividades frente as unidades federativas na mesma região.

\section{Resultados e Discussão}

$\mathrm{Na}$ análise dos resultados para 2004, de acordo com as informações do quadro 1, é possível notar que no Espírito Santo, houve um QL>1 no setor F e G, que se referem a Construção Civil e Comércio respectivamente. Em Minas Gerais, os setores, C, E, L-N, Q e R apresentaram QL>1, sendo o setor E, responsável por Água, Esgoto e Gestão de Resíduos Sólidos foi o que apresentou maior especialização em operações contratadas. No estado do Rio de Janeiro, os setores F, I, L-N, Q e S, foram os que apresentaram o $Q L>1$, sendo o setor $Q$, que representa Saúde, o que apresentou o maior grau de especialização. Em São Paulo os setores A, B, G, H, I, L-N e $R$ apresentaram o $Q L>1$, sendo o setor $A$ e $B$ os que apresentaram o maior grau de especialização, estando os dois setores, Agricultura e indústria Extrativa, com o mesmo QL, 3,25. É possível visualizar que que o setor $\mathrm{L}-\mathrm{N}$, responsável por atividades imobiliárias, profissionais e administrativas, apresentou QL>1 em todos os estados.

Na região Sul do país, o estado do Paraná apresentou QL>1 nos setores C, G P e S. Em Santa Catarina os setores C, H e R foram os que apresentaram o QL>1, no qual o setor $\mathrm{H}$, que representa Transporte, Armazenagem e Correio, foi o que apresentou maior QL. É possível visualizar que que o setor $C$, responsável pela indústria de transformação, apresentou $Q \mathrm{~L}>1$ nos estados do Maranhão $\mathrm{e}$ Pernambuco. 
Na região Nordeste, o estado de Alagoas apresentou QL>1 nos setores F e G, sendo o setor $F$ ligado a Construção, aquele que apresentou maior especialização. $\mathrm{Na}$ Bahia, os setores F, G, J, L-N e P foram os que apresentaram QL $>1$, sendo o setor $P$ ligado a Educação a atividade de maior especialização. No Ceará, os setores L-N e $S$, foram os que apresentaram $Q \mathrm{~L}>1$, sendo o setor $\mathrm{S}$, o que obteve maior $\mathrm{QL}$, demonstrando um algo grau de especialização em Outras Atividades de Serviço. No Maranhão, os setores $\mathrm{C}$ e $\mathrm{G}$, Indústria de Transformação e Comércio respectivamente, foram os que apresentaram o $Q L>1$, estando o setor $G$ o que apresentou maior QL. Na Paraíba, os setores J e L-N foram os que apresentaram $\mathrm{QL}>1$, sendo que o setor $\mathrm{L}-\mathrm{N}$ que representa as atividades imobiliárias, científicas e administrativas. Em Pernambuco, os setores $\mathrm{C}$ e L-N foram os que apresentaram QL>1, sendo que o setor L-N foi o que apresentou o maior QL. No Piauí, o setor I foi o único que apresentou $Q L>1$, sendo este setor ligado a alojamento e alimentação. No Rio Grande do Norte, o setor I foi o único que apresentou QL>1, sendo este setor ligado a alojamento e alimentação. Em Sergipe, o setor Q foi o único que apresentou QL>1, sendo este setor ligado a saúde humana e serviços sociais. É possível visualizar que o setor $\mathrm{Q}$ é predominante na região que apresente $\mathrm{Q} \mathrm{L}>1$.

Na região Centro-Oeste, o Distrito Federal apresentou 5 atividades com o QL>1, sendo eles o setor C, ligado a indústria de transformação, o setor $J$ representando informação e comunicação, setor L-N ligado a atividades imobiliárias, científicas e administrativas, setor $\mathrm{P}$, representando a educação e o setor $\mathrm{S}$ representando outros, sendo este penúltimo o que apresentou o maior QL. Em Goiás, os setores $\mathrm{D}, \mathrm{F}, \mathrm{G}$ e L-N foram os que apresentaram $\mathrm{QL}>1$, sendo o setor $\mathrm{D}$, ligado a Eletricidade e Gás, o que apresentou o maior quociente locacional dentre as atividades do estado. No Mato Grosso, os setores C, G e L-N, obtiveram o QL>1, sendo o setor L-N ligado a atividades imobiliárias, científicas e administrativas, o que apresentou maior quociente locacional. No Mato Grosso do Sul, os setores G, I, J, L$\mathrm{N}$ e $\mathrm{S}$ foram os que apresentaram $\mathrm{QL}>1$, sendo o setor $\mathrm{S}$, ligado a outras atividades de serviços, o que apresentou o maior quociente locacional. É possível visualizar que que o setor L-N, responsável por atividades imobiliárias, profissionais e administrativas, apresentou QL>1 em todos os estados.

Na região Norte, o estado do Acre não apresentou nenhuma atividade com QL>1, devido a inutilização do cartão BNDES no estado durante o ano de 2004. No Amapá, o setor $G$ foi o único que apresentou $Q L>1$, sendo este ligado as atividades de comércio e reparação de automóveis. No Amazonas, os setores $\mathrm{G}$ e Q, obtiveram QL>1, sendo o setor Q, ligado a saúde humana e serviços sociais, o que apresentou o maior quociente. No Pará, os setores $\mathrm{F}$ e L-N foram os que apresentaram o maior quociente, sendo setor $\mathrm{F}$ ligado a construção civil, o que apresentou o maior quociente. Em Rondônia, os setores $C$, J e $S$ foram os que apresentaram $Q L>1$, sendo que o setor $J$ ligado a informação e comunicação foi o que apresentou 0 maior quociente locacional. Em Roraima não houve nenhuma atividade com QL>1, devido a inutilização do cartão BNDES no estado durante o ano de 2004. No Tocantins, os setores I e L-N foram os que apresentaram $L-N>1$, sendo que o setor I apresentou o maior quociente locacional. É possível visualizar que não existe um setor predominante na região que apresente $Q L>1$, demonstrando uma diversificação entre os estados na utilização do cartão. 
Quadro 1. Dados do quociente locacional a partir do valor contratado no cartão BNDES em 2004 para as unidades federativas do Brasil

\begin{tabular}{|c|c|c|c|c|c|c|c|c|c|c|c|c|c|c|c|c|c|}
\hline \multirow{2}{*}{ UF } & \multicolumn{17}{|c|}{ CLASSIFICAÇÃO NACIONAL DE ATIVIDADES ECONÔMICAS - CNAE } \\
\hline & A & B & c & D & E & $\mathrm{F}$ & G & $\mathrm{H}$ & I & $\mathrm{J}$ & $\mathrm{K}$ & L-N & 0 & $\mathrm{P}$ & Q & $\mathrm{R}$ & $\mathrm{s}$ \\
\hline ES & - & - & - & - & - & 4,5 & 2,0 & - & - & - & - & - & - & - & - & - & - \\
\hline MG & - & - & 1,8 & - & 4,8 & 0,7 & 0,7 & 0,5 & 0,4 & 0,6 & - & 1,1 & - & - & 1,1 & 2,4 & 0,6 \\
\hline RJ & - & - & 0,4 & - & - & 2,4 & 1,0 & 0,6 & 1,4 & 0,9 & - & 1,2 & - & 0,4 & 3,7 & - & 1,7 \\
\hline SP & 3,3 & 3,3 & 0,7 & - & 0,6 & 0,8 & 1,1 & 1,5 & 1,6 & 1,0 & - & 1,0 & - & 0,1 & 0,4 & 1,3 & 0,5 \\
\hline PR & - & - & 1,8 & - & - & - & 1,0 & 0,6 & - & 0,7 & - & - & - & 2,2 & 0,6 & - & 3,1 \\
\hline $\mathrm{RS}$ & - & - & 1,9 & - & - & - & 0,6 & 3,6 & 0,5 & 1,0 & - & 0,9 & - & - & - & 3,3 & 0,7 \\
\hline SC & - & - & 1,1 & 8,2 & 1,7 & - & 1,1 & 1,6 & 1,8 & - & - & 0,2 & - & - & 1,5 & - & 2,5 \\
\hline $\mathrm{AL}$ & - & - & 0,8 & - & - & 14,0 & 1,1 & - & - & - & - & - & - & - & - & - & - \\
\hline BA & - & - & 0,4 & - & - & 3,5 & 1,3 & 0,5 & 0,1 & 1,3 & - & 1,1 & - & 9,5 & - & - & - \\
\hline $\mathrm{CE}$ & - & - & 1,0 & - & - & - & 0,7 & - & - & - & - & 2,5 & - & - & - & - & 5,2 \\
\hline MA & - & - & 1,4 & - & - & - & 1,6 & - & - & - & - & - & - & - & - & - & - \\
\hline PB & - & - & 0,8 & - & - & - & 0,3 & - & - & 16,2 & - & 2,2 & - & - & - & - & - \\
\hline $\mathrm{PE}$ & - & - & 1,8 & - & - & - & 0,1 & - & - & - & - & 3,9 & - & - & - & - & 0,8 \\
\hline $\mathrm{PI}$ & - & - & - & - & - & - & - & - & 22,9 & - & - & - & - & - & - & - & - \\
\hline $\mathrm{RN}$ & - & - & - & - & - & - & - & - & 22,9 & - & - & - & - & - & - & - & - \\
\hline SE & - & - & 0,1 & - & - & - & 0,3 & - & - & - & - & - & - & - & 26,2 & - & - \\
\hline $\mathrm{DF}$ & - & - & 1,4 & - & - & - & 0,8 & - & - & 1,3 & - & 1,0 & - & 18,2 & - & - & 2,0 \\
\hline GO & - & - & - & 17,5 & - & 1,3 & 1,7 & - & - & - & - & 1,3 & - & - & - & - & - \\
\hline MT & - & - & 1,1 & - & - & - & 1,0 & 0,3 & 0,4 & 0,6 & - & 1,9 & - & - & - & - & - \\
\hline MS & - & - & 0,2 & - & - & - & 1,4 & - & 1,8 & 2,5 & - & 1,1 & - & - & - & - & 3,0 \\
\hline$A C$ & - & - & - & - & - & - & - & - & - & - & - & - & - & - & - & - & - \\
\hline AP & - & - & - & - & - & - & 2,3 & - & - & - & - & - & - & - & - & - & - \\
\hline $\mathrm{AM}$ & - & - & - & - & - & - & 1,5 & - & - & - & - & 0,5 & - & - & 9,1 & - & - \\
\hline PA & - & - & - & - & - & 15,3 & 0,4 & - & - & - & - & 3,6 & - & - & - & - & - \\
\hline RO & - & - & 1,6 & - & - & - & 0,9 & - & - & 3,4 & - & 0,8 & - & - & - & - & 2,6 \\
\hline $\mathrm{RR}$ & - & - & - & - & - & - & - & - & - & - & - & - & - & - & - & - & - \\
\hline TO & - & - & - & - & - & - & 0,8 & - & 9,2 & - & - & 1,9 & - & - & - & - & - \\
\hline
\end{tabular}

Fonte: Elaboração própria.

\subsection{Análise Dos Resultados Para 2014}

Tendo por base as informações do quadro 2, na região Sudeste, o estado do Espírito Santo apresentou 9 setores com o QL>1, foram eles as atividades B, C, D, E, F, J, Q, R e S, demonstrando uma especialização nesse setor no que se refere a utilização do cartão BNDES, sendo o setor E ligado a água, esgoto e gestão de resíduos foi o que apresentou o maior quociente locacional. Em Minas Gerais, os setores A, B, H, J, K, L-N, O, P, Q, R e S obtiveram Q L>1, sendo que o setor O ligado a administração pública, defesa e seguridade social foi o que apresentou o maior quociente locacional. No Rio de Janeiro, os setores E, F, I, J, K, L-N, P, Q, R e S apresentaram o QL>1 demonstrando uma especialização nessas atividades no que tange a utilização do cartão BNDES, sendo que o setor $\mathrm{E}$, ligado a água, esgoto e gestão de resíduos foi o que apresentou o maior quociente locacional. Em São Paulo, os setores C, D, E, H, I, J, K, L-N, P, R e S apresentaram o QL $>1$, sendo que o setor $\mathrm{K}$, ligado a atividades financeiras, de seguros e serviços relacionados foi a que 
apresentou o maior quociente locacional. É possível visualizar que que os setores J, responsável por informação e comunicação, Q, responsável por saúde humana e serviços sociais, $R$, responsável arte, cultura, esporte e recreação e $S$, outras atividades e serviços, apresentaram $\mathrm{QL}>1$ em todos os estados.

Na região Sul, o estado do Paraná apresentou 4 setores que obtiveram o $\mathrm{Q} L>1$, foram eles, os setores $\mathrm{C}, \mathrm{H}, \mathrm{K}$ e $\mathrm{P}$, demonstrando que essas atividades apresentaram uma especialização no que tange as operações do cartão BNDES nos estado, sendo que o setor $\mathrm{H}$ ligado a transporte, armazenagem e correio obteve $\mathrm{O}$ maior QL. Em Santa Catarina, os setores B, C, D, E, F, H e J foram o que obtiver o $Q \mathrm{~L}>1$, sendo que o setor $\mathrm{D}$ ligado a eletricidade e Gás, apresentou o maior quociente locacional. No Rio Grande do Sul, os setores B, C, D, E, H, I e R obtiveram o QL>1, sendo que o setor $\mathrm{D}$, ligado a eletricidade e gás, apresentou o maior quociente locacional. É possível visualizar que que o setor $C$, responsável pela indústria de transformação, e o setor $\mathrm{H}$ responsável por transporte, armazenagem e correio, apresentaram $\mathrm{QL}>1$ em todos os estados.

$\mathrm{Na}$ região Nordeste, o estado de Alagoas apresentou 7 setores que obtiveram o QL>1, ou seja, setores que demonstram uma especialização no que tange a contratação de operações do cartão BNDES, sendo que o setor $K$ responsável por atividades financeiras, de seguros e serviços relacionados foi a atividade que obteve o maior quociente locacional, apresentando uma robustez na especialização frente aos outros setores. Na Bahia, os setores $A, G, L-N, Q$ e $S$ obtiveram um $Q \mathrm{~L}>1$, sendo que o setor $A$ ligado a agricultura, pecuária, pesca, produção florestal e aquicultura obteve o maior quociente locacional dentre os setores do estado, demonstrando uma maior especialização nesta atividade. No Ceará, os setores $A, B, G, P$ e $S$ obtiveram um $Q L>1$, sendo que o setor $G$, ligado a comércio, reparação de veículos automotores e motocicletas obteve o maior quociente locacional dentre os setores do estado, demonstrando uma maior especialização nesta atividade. No Maranhão, os setores B, D, G e Q obtiveram um $Q L>1$, sendo que o setor $D$, ligado a eletricidade e gás, obteve o maior quociente locacional dentre os setores do estado, demonstrando uma maior especialização nesta atividade.

Na Paraíba, os setores A, E, F, G e J obtiveram o QL>1, demonstrando uma especialização no que tange as operações do cartão BNDES no estado. Dentre os setores citados, a atividade econômica $F$ ligado a construção, foi a que apresentou maior quociente locacional, demonstrando uma maior robustez na especialização desse setor. Em Pernambuco, os setores E, F, G, I, J, L-N, P, Q e S obtiveram um $Q L>1$, sendo que o setor $S$, ligado a outras atividades de serviços, obteve o maior quociente locacional dentre os setores do estado.

No Piauí, os setores F, G P, Q e S obtiveram o QL>1, sendo que o setor $\mathrm{P}$, ligado a Educação, foi a que apresentou maior quociente locacional. No Rio Grande do Norte, os setores A, B, F, G, I, L-N e S apresentaram um QL>1, demonstrando uma especialização nas operações do cartão BNDES, nesses setores, sendo que o setor $B$, ligado a indústrias extrativas, obteve o maior quociente locacional dentre os setores do estado. Em Sergipe, os setores A, E, G, L-N, Q, R e S foram os que apresentaram $\circ \mathrm{Q} \mathrm{L}>1$, sendo que o setor $\mathrm{R}$, ligado a artes, cultura, esporte $\mathrm{e}$ recreação, obteve o maior quociente locacional. É possível visualizar que o setor $G$, 
responsável pelo comércio, reparação de veículos automotores e motocicletas, apresentaram QL>1 em todos os estados.

$\mathrm{Na}$ região Centro-Oeste, o Distrito Federal apresentou 11 setores que obtiveram o QL>1, ou seja, setores que demonstram uma especialização no que tange a contratação de operações do cartão BNDES, sendo que no estado o setor R, ligado a artes, cultura, esportes e recreação apresentou o maior quociente locacional. Em Goiás, os setores A, B, D, F, G e R, obtiveram o QL $>1$, demonstrando uma especialização no que tange as operações realizadas pelo cartão BNDES no estado, sendo que o setor $D$, ligado a eletricidade e gás obteve o maior quociente locacional entre as atividades do estado. No Mato Grosso, os setores A, B, G, H, I, K, $\mathrm{O}$ e $\mathrm{P}$ obtiveram o $\mathrm{Q} \mathrm{L}>1$, sendo que o setor $\mathrm{O}$, ligado a administração pública, defesa e seguridade pessoal, obteve o maior quociente locacional dos setores no estado. No Mato Grosso do Sul, os setores A, B, D, E, G, H, J, Q e S obtiveram o QL>1, sendo que o setor $D$, ligado a eletricidade e gás foi o que apresentou o maior quociente locacional. É possível visualizar que o setor $G$, responsável pelo comércio, reparação de veículos automotores e motocicletas, e o setor A, responsável pela agricultura, pecuária, produção florestal e aquicultura, apresentaram $Q \mathrm{~L}>1$ em todos os estados.

Na região Norte, o Acre apresentou 5 setores em que obteve o QL $>1$. Neste estado, o setor que apresentou maior quociente locacional, foi o setor $\mathrm{F}$, ligado a construção, demonstrando uma especialização mais robusta neste setor. No Amapá, os setores E, F, G, J e P apresentaram o QL>1. No Amazonas, os setores E, F, G, H e Q apresentaram o QL>1. No Pará, os setores A, F, G, Q e S, apresentaram o $Q L>1$, sendo que o setor $S$, ligado a outras atividades de serviços, obteve o maior quociente locacional dos setores no estado. Em Rondônia, as atividades que apresentaram o Q $>>1$ foram os setores $B, F, G$ e Q, sendo que o setor $B$, ligado a indústrias extrativas, foi o que apresentou maior quociente locacional. Em Roraima, as atividades que apresentaram o $Q \mathrm{~L}>1$, foram os setores $F, G$ e $S$, sendo que $O$ setor $\mathrm{S}$, ligado a outras atividades de serviços, foi o que apresentou maior quociente locacional dos setores no estado. No Tocantins, os setores B, F, G, L-N e Q apresentaram o $Q \mathrm{~L}>1$, sendo que o setor $\mathrm{B}$, ligado a indústrias extrativas, obteve $\mathrm{O}$ maior quociente locacional dos setores no estado. É possível visualizar que que os setores G, responsável pelo comércio, reparação de veículos automotores e motocicletas, e o setor $F$, responsável pela construção, apresentaram QL>1 em todos os estados. 
Quadro 2. Dados do quociente locacional a partir do valor contratado no cartão BNDES em 2014 para as unidades federativas do Brasil

\begin{tabular}{|c|c|c|c|c|c|c|c|c|c|c|c|c|c|c|c|c|c|}
\hline \multirow[b]{2}{*}{ UF } & \multicolumn{17}{|c|}{ CLASSIFICAÇÃO NACIONAL DE ATIVIDADES ECONÔMICAS - CNAE } \\
\hline & A & B & C & D & $\mathrm{E}$ & $\mathrm{F}$ & G & $\mathrm{H}$ & I & J & K & L-N & 0 & $P$ & $\mathrm{Q}$ & $R$ & S \\
\hline ES & 0,4 & 1,5 & 1,1 & 1,0 & 1,4 & 1,2 & 1,0 & 0,8 & 0,9 & 1,0 & 0,2 & 0,9 & - & 0,9 & 1,3 & 0,4 & 1,5 \\
\hline MG & 1,2 & 1,4 & 1,0 & - & 0,5 & 1,0 & 1,0 & 1,1 & 1,0 & 1,2 & 1,1 & 1,0 & 6,5 & 1,0 & 1,2 & 1,2 & 1,4 \\
\hline RJ & 0,4 & 0,6 & 0,6 & 0,4 & 1,9 & 1,1 & 1,0 & 0,7 & 1,9 & 1,6 & 1,5 & 1,4 & - & 1,5 & 1,4 & 0,4 & 0,6 \\
\hline SP & 0,8 & 0,7 & 1,2 & 1,1 & 1,1 & 0,8 & 0,9 & 1,1 & 1,1 & 1,2 & 1,7 & 1,1 & - & 1,2 & 1,0 & 0,8 & 0,7 \\
\hline PR & 0,7 & $\begin{array}{l}0, \\
9\end{array}$ & 1,3 & 0,2 & 0,7 & 0,9 & 0,9 & 1,2 & 0,9 & 0,8 & 1,1 & 0,9 & - & 1,0 & 0,8 & 0,7 & 0,9 \\
\hline $\mathrm{RS}$ & 0,9 & 1,0 & 1,6 & 2,7 & 1,5 & 1,2 & 0,8 & 1,2 & 0,9 & 1,1 & 0,4 & 0,8 & - & 0,6 & 0,4 & 0,9 & 1,0 \\
\hline SC & 0,9 & 1,0 & 1,4 & 2,3 & 1,4 & 1,0 & 0,9 & 1,2 & 1,0 & 0,9 & 0,8 & 0,8 & - & 0,7 & 0,7 & 0,9 & 1,0 \\
\hline $\mathrm{AL}$ & 0,2 & - & 0,6 & - & 1,2 & 1,3 & 1,1 & 0,8 & 1,1 & 0,6 & 2,7 & 1,6 & - & 0,8 & 1,2 & 0,2 & - \\
\hline BA & 1,7 & 0,7 & 0,5 & 0,5 & 0,7 & 0,9 & 1,2 & 1,0 & 0,9 & 0,8 & 0,4 & 1,2 & - & 0,9 & 1,5 & 1,7 & 0,7 \\
\hline CE & 1,1 & 1,1 & 0,9 & - & 0,7 & 1,0 & 1,2 & 0,6 & 0,7 & 0,9 & 0,4 & 0,8 & - & 1,1 & 0,5 & 1,1 & 1,1 \\
\hline MA & 0,7 & 2,3 & 0,4 & 2,8 & 0,4 & 1,0 & 1,4 & 0,7 & 0,6 & 0,5 & 0,1 & 0,8 & - & 0,9 & 1,4 & 0,7 & 2,3 \\
\hline PB & 2,0 & 0,2 & 0,8 & - & 1,5 & 2,6 & 1,0 & 0,4 & 0,7 & 2,0 & 0,6 & 0,9 & - & 0,6 & 0,9 & 2,0 & 0,2 \\
\hline $\mathrm{PE}$ & 0,5 & $\begin{array}{l}0, \\
9\end{array}$ & 0,9 & - & 1,1 & 1,1 & 1,1 & 0,7 & 1,1 & 1,1 & 0,5 & 1,1 & - & 1,3 & 1,2 & 0,5 & 0,9 \\
\hline $\mathrm{PI}$ & 0,9 & $\begin{array}{l}0, \\
4\end{array}$ & 0,5 & - & 0,5 & 1,3 & 1,3 & 0,6 & 0,6 & 0,5 & 0,2 & 0,8 & - & 1,8 & 1,1 & 0,9 & 0,4 \\
\hline $\mathrm{RN}$ & 2,3 & 4,1 & 0,4 & - & 0,1 & 1,8 & 1,2 & 0,5 & 1,0 & 0,8 & 0,5 & 1,2 & - & 0,6 & 0,7 & 2,3 & 4,1 \\
\hline SE & 2,0 & - & 0,9 & - & 1,1 & 0,6 & 1,0 & 1,0 & 1,0 & 0,9 & - & 1,5 & - & 0,6 & 1,1 & 2,0 & - \\
\hline DF & 1,2 & 0,1 & 0,5 & - & 0,9 & 1,3 & 1,1 & 0,6 & 1,5 & 1,2 & 1,2 & 1,5 & - & 1,4 & 1,0 & 1,2 & 0,1 \\
\hline GO & 1,8 & 1,2 & 0,8 & 1,9 & 0,7 & 1,1 & 1,2 & 0,9 & 0,7 & 0,6 & 0,6 & 0,9 & - & 0,8 & 0,8 & 1,8 & 1,2 \\
\hline MT & 1,7 & 1,9 & 0,6 & - & 0,9 & 0,8 & 1,2 & 1,3 & 1,0 & 0,7 & 1,3 & 0,8 & 11,9 & 1,1 & 0,9 & 1,7 & 1,9 \\
\hline MS & 1,8 & 1,6 & 0,6 & 6,5 & 1,1 & 1,0 & 1,2 & 1,2 & 0,9 & 1,0 & 0,7 & 0,9 & - & 1,0 & 1,1 & 1,8 & 1,6 \\
\hline$A C$ & 0,3 & - & 0,5 & - & 1,5 & 3,1 & 1,2 & 0,5 & 0,6 & 0,3 & 2,8 & 1,0 & - & 0,2 & 1,2 & 0,3 & - \\
\hline AP & - & - & 0,3 & - & 5,9 & 1,6 & 1,4 & 0,3 & 0,6 & 1,5 & 0,9 & 0,6 & - & 1,6 & 0,2 & - & - \\
\hline AM & 0,8 & - & 0,8 & - & 1,4 & 1,1 & 1,2 & 1,1 & 0,7 & 0,3 & 0,1 & 0,6 & - & 0,4 & 1,9 & 0,8 & - \\
\hline PA & 1,2 & 1,0 & 0,4 & - & 0,4 & 1,2 & 1,4 & 0,7 & 0,5 & 0,5 & 0,1 & 1,0 & - & 1,0 & 1,4 & 1,2 & 1,0 \\
\hline RO & 0,3 & 1,3 & 0,7 & 0,2 & 0,4 & 1,2 & 1,2 & 0,6 & 0,7 & 0,7 & - & 0,9 & - & 0,6 & 1,5 & 0,3 & 1,3 \\
\hline $\mathrm{RR}$ & 0,4 & - & 0,3 & - & - & 1,3 & 1,6 & 0,2 & 0,5 & 0,2 & - & 0,8 & - & 0,3 & 0,1 & 0,4 & - \\
\hline TO & 0,6 & $\begin{array}{l}4, \\
9\end{array}$ & 0,4 & - & 0,7 & 2,0 & 1,2 & 0,8 & 1,0 & 0,5 & 0,3 & 1,1 & - & 0,7 & 1,2 & 0,6 & 4,9 \\
\hline
\end{tabular}

Fonte: Elaboração própria.

\subsection{Análise das Desigualdades entre Variáveis Selecionadas}

Para a construção da figura, adaptou-se a curva de Lorenz para que fossem inseridas outras variáveis. Foram selecionados os dados da população, fornecidos pelo Instituto Brasileiro de Geografia e Estatística (IBGE), o Produto Interno Bruto (PIB), também fornecido pelo IBGE, a quantidade de Micro, Pequenas e Médias Empresas (MPMEs) fornecido pelo IBGE, além do valor das operações contratadas pelo cartão BNDES. Os dados foram tratados e agrupados de forma a possibilitar a construção da curva de Lorenz. 
Figura 1. Distribuição das variáveis acumuladas pelas unidades federativas para os dados de 2004

2004

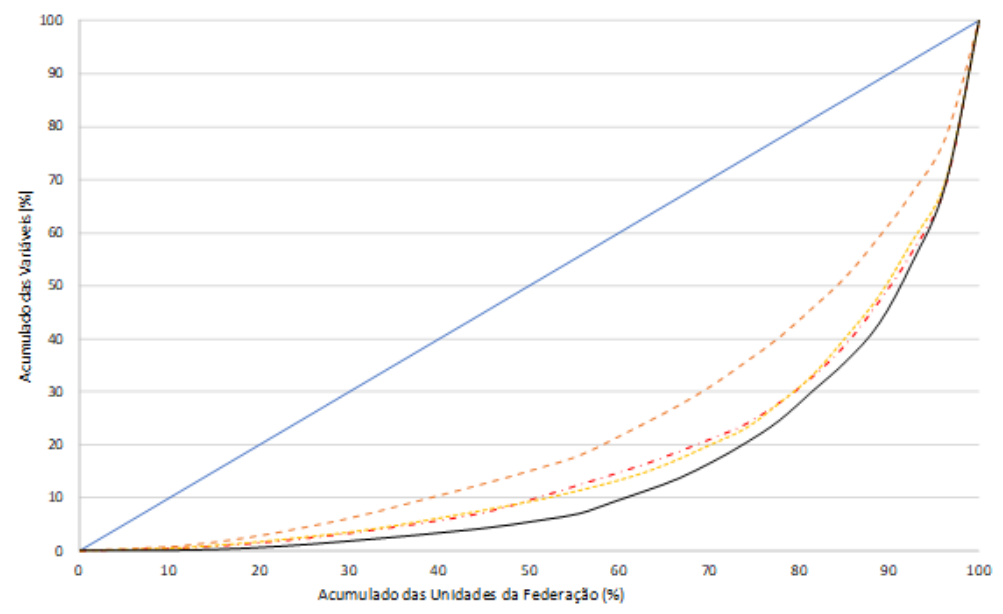

Fonte: Elaboração própria.

Para 2004, é possível visualizar que existe uma concentração das variáveis em uma pequena quantidade de estados, estando eles nas regiões Sudeste e Sul. No que tange a população, verifica-se dentre as variáveis analisadas, é a que apresenta menor desigualdade na sua distribuição, todavia, ainda assim apresentam uma desproporcionalidade no arranjo populacional nos estados. Em relação ao PIB, é possível observar que também ocorre uma concentração nas regiões Sul e Sudeste, sendo que essas duas regiões acumulavam $73 \%$ do PIB.

Quando se trata das MPMES, observa-se uma oscilação no que se refere a presença dessas organizações nas unidades federativas do país, já que quando se trabalha apenas com as regiões Sudeste e Sul, os estados dessas regiões juntos, acumulavam $74 \%$ de todas as MPMEs do país. A curva referente ao valor das operações contratadas do cartão BNDES, também demonstra uma oscilação em relação às outras curvas. Em 2004, quando se analisa apenas as regiões Sudeste e Sul, as duas juntas acumularam $76 \%$ do total do valor de operações contratados, frente às outras variáveis, no que tange essas duas regiões, é o maior valor percentual, o que acaba sendo refletido na figura, já que essa curva é a que se apresenta mais longe do eixo de igualdade. 
Figura 2. Distribuição das variáveis acumuladas pelas unidades federativas para os dados de 2014

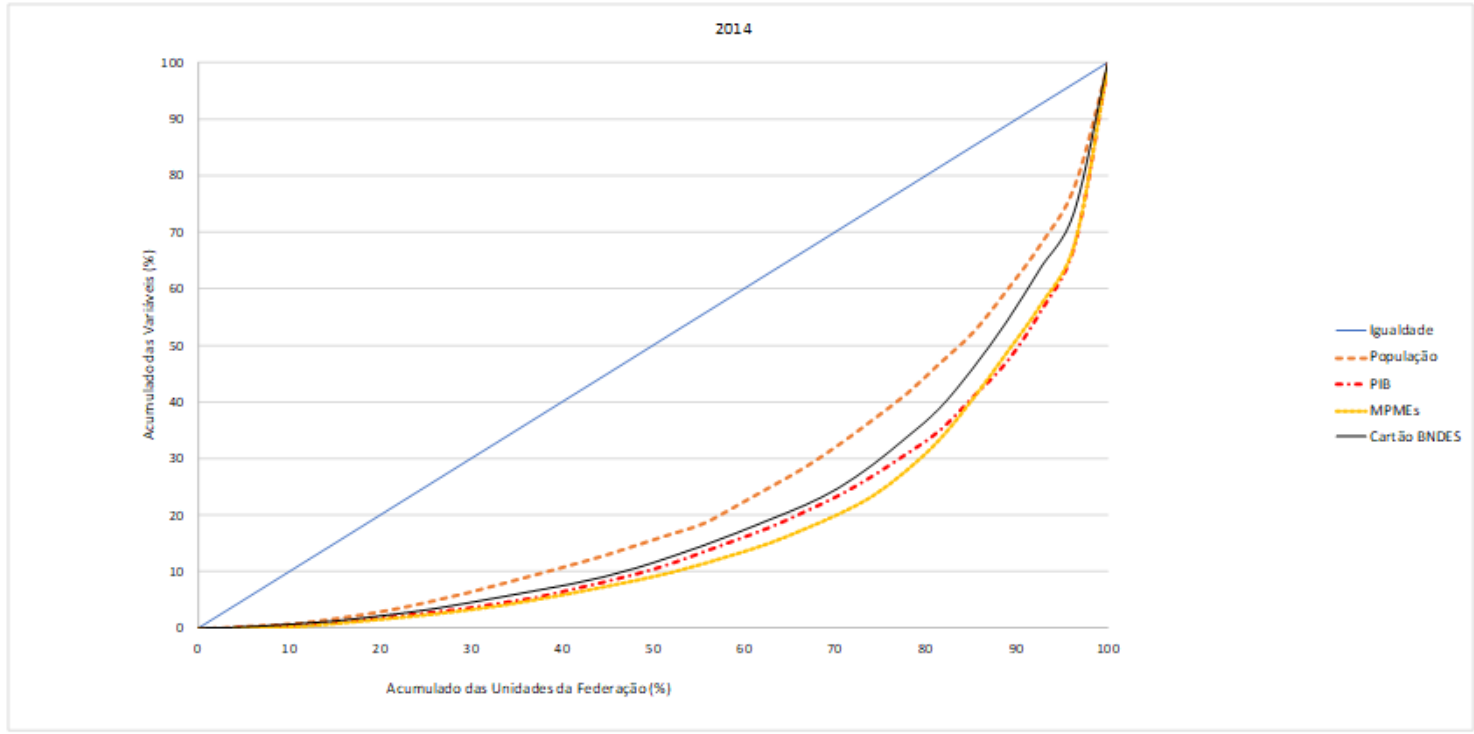

Fonte: Elaboração própria.

Quando se analisa apenas a região Sudeste e Sul, se sabe que o acumulado das unidades federativas é $25 \%$, que juntos acumulam $42 \%$ da população brasileira, uma redução frente a 2004. No gráfico é possível perceber que à medida que outras regiões são incluídas, ocorre uma inclinação da curva, demonstrando que essas outras regiões exercem uma parcela significativa no acumulado da população. Quando analisado a inserção da região Nordeste e Centro-Oeste, o acumulado das quatro regiões foi para $91 \%$ da população mostrando uma baixa variação frente a 2004.

Em relação a 2014, o PIB brasileiro continua apresentando uma concentração na região Sudeste e Sul, todavia, em relação a 2004 ele apresentou uma leve queda, dos 73\% em 2004 para 71\% em 2014. A trajetória da curva, assim como as outras variáveis, começa com uma inclinação horizontal, e a medida da inserção das outras regiões vai se inclinando verticalmente, demonstrando que a participação dessas regiões é menos representativa.

Quando se analisa as regiões Sudeste e Sul, observa-se que $74 \%$ dessas organizações se concentram nessas regiões, sendo que quando se inclui a região nordeste, esse número salta para $88 \%$, e vai para $96 \%$ quando se inclui a região Centro-Oeste. Em relação ao acumulado, as regiões Sudeste e Sul ainda concentram boa parte das operações, acumulando 68\%, uma redução frente aos 76\% de 2004 para essas duas regiões. É importante notar que quando se acrescenta a região Nordeste, o número salta $84 \%$, o mesmo de 2004 , mostrando que houve um aumento na participação da região na utilização do cartão.

Quando abordado o comportamento do nível de recursos do cartão BNDES destinado para a indústria, comércio e serviços, observa-se um desempenho diferente entre os estados, principalmente quando comparamos as regiões Sul e Sudeste, com o Norte, Nordeste e Centro-Oeste. Enquanto que em 2004, estados como São Paulo, Minas Gerais e Santa Catarina apresentaram QL>1 em diversos setores, o mesmo não acontece nas outras regiões, tendo os estados do Centro- 
Oeste um resultado levemente superior a Norte e Nordeste, mas ainda aquém do Sul e Sudeste. Nos resultados de 2014 percebe-se uma melhoria nesse quadro, ainda que o comportamento regional aponte a continuação de uma predominância do Sul e Sudeste, no que se refere ao nível de operações do cartão BNDES. Entretanto, houve aumento da participação das regiões Norte, Nordeste e Centro-Oeste nas operações do cartão tendo por base o número de setores com QL>1 como os setores da agricultura, indústria extrativista, Eletricidade, gás, água, esgoto, construção, comércio, administração pública, saúde humana, outras atividades/serviços,sendo os estados do Centro-Oeste os que apresentam melhor resultado das três regiões citadas. Assim sendo, nota-se que a desconcentração averiguada em 2014 se comparado com 2004 se deve ao aumento da demanda pelos recursos do cartão pelas regiões Centro-Oeste, Nordeste e Norte, principalmente, no setor de serviços.

Com o lançamento do cartão BNDES ocorrido em 2002, as primeiras operações apenas foram ocorrer em 2003, sendo que as atividades registradas no cartão neste ano não apresentaram uma alta relevância em distribuição nacional. A partir de 2004 é que as operações começaram a ocorrer em quase todas as unidades da federação e do Distrito Federal, estando apenas o estado do Acre e Roraima sem a contratação de operações neste ano (BNDES, 2004).

Apesar da alta das contratações e uma maior inserção do uso do cartão por outras regiões, ainda sim se observa uma concentração na utilização do cartão nas regiões Sul e Sudeste. Um dos motivos que podem elencar a razão dessa concentração é a forma que o cartão é emitido, uma vez que em 2004 apenas o Bradesco e o Banco do Brasil faziam essa emissão, e apesar de serem bancos com uma alta presença por todo o território nacional, ainda era necessária uma divulgação desse produto por meio de seus funcionários e também pelo governo (BNDES, 2004).

Um outro fator que influencia a questão dessa concentração, é o número de micro, pequenas e médias empresas nas regiões brasileiras. Os grandes centros financeiros do país estão nas regiões Sul e Sudeste, e em 2004, essas duas localidades concentravam $74 \%$ de todas as MPME's do país. Estar baseado nesses grandes centros, coloca esses estabelecimentos em um mercado mais estruturado e com maior oferta de crédito. Ao se analisar a cobertura do cartão, nota-se que em 2004 ele não atendia todos os municípios brasileiros, sendo que isso foi um trabalho contínuo do BNDES no decorrer dos anos para poder aumentar a sua cobertura (BNDES, 2004).

Esta observação está em linhacom Hirt (2019), que discorre sobre o fortalecimento do cartão BNDES nas operações automáticas como instrumento do banco, sendo que foi observado no que tange às operações uma elevação da concentração na região Sudeste, que estava em segundo lugar desde 1997 e está em primeiro lugar a partir de 2008. Este fato aconteceu em virtude da elevação da demanda no Sudeste, principalmente, nos estados de Minas Gerais, São Paulo e em menor nível o Rio de Janeiro. Com relação ao estado do Sul, houve queda das demandas neste período, sobremaneira nos estados do Paraná e Rio Grande do Sul. A elevação progressiva das operações nas outras regiões fez com que a concentração no sudeste não fosse maior. De 2005 em diante, houve uma lenta elevação nas demandas na região Nordeste, destacando-se Ceara, Pernambuco e 
Bahia. No Centro-Oeste também se observou uma pequena elevação, sendo que as maiores demandas são provenientes dos estados de Mato Grosso e Goiás. Na região Norte, ocorreu crescimento das demandas por operações automáticas, principalmente no estado do Amapá. oram ofertados em pouco mais de dois anos mais de 50 mil cartões e os valores dos créditos concedidos acima de R\$ 1 bilhão, com limite médio de crédito de $\mathrm{R} \$ 21,7$ mil. Os gastos por intermédio do cartão BNDES, em percentuais, obtiveram uma elevação de 491\% de 2004 a 2005. Essa melhora no desempenho do cartão é resultado de inúmeras ações colocadas em prática ao longo de 2005, com a meta de elevar o alcance dessa linha, tais como a propaganda para propiciar informações ao usuário, elevação dos prazos e limites de crédito (HIRT, 2019).

De acordo com BNDES (2005), explica-se este aumento da demanda a partir de 2005 a volta do BNDES, por meio da realização de campanhas publicitárias com a meta de fazer o Banco e seus produtos que possuem maior proximidade do conjunto da sociedade e de seus potenciais clientes. Foram feitas três campanhas de envergadura: Uma sobre Papéis de índice Brasil Bovespa (PIBB) e outra sobre o cartão BNDES.

Segundo BNDES (2005), com relação aos procedimentos operacionais, também foi elaborado e inserido novos procedimentos com o objetivo de elevar a demanda pelo cartão BNDES, tendo por destaque:

1) Agilização no controle e emissão de certidões com a Caixa Econômica Federal (informações sobre o Certificado de Regularidade do Fundo de Garantia do Tempo de Serviço - FGTS) e o Banco Central (obtenção sistemática das inscrições no Cadastro Informativo dos Créditos Não-Quitados de Órgãos de Entidades Federais - Cadin ) por intermédio da celebração de convênios.

2) Aumento em $100 \%$ do limite de crédito do Cartão BNDES para $\mathrm{R} \$ 100 \mathrm{mil}$

3) Inserção de novos prazos para financiamento, incluindo-se 36 meses, além de 12,18 e 24 meses.

4) Para as empresas que desenvolvem software, realização de credenciamento para a Linha Prosoft Comercialização.

5) A inserção de fabricantes de papel de escrever e imprimir para edição de livros no relacionamento de fornecedores autorizados.

6) A definição no portal de operações do BNDES do módulo de inclusão de distribuidores autorizados.

O indicador de evolução do apoio do Cartão BNDES a empresas, para o período de 2007 a 2012, está presente na tabela 1. Levando-se em consideração a totalidade das empresas que recebem o financiamento por intermédio deste cartão, nota-se uma elevação na participação do BNDES de 0,8\% em 2007 para 7,2\% em 2012, o que denota um valor no término do período nove vezes superior. O crescimento do acesso ao cartão mostra o potencial deste produto para acarretar crescimento do apoio do BNDES às empresas, principalmente, as pequenas e micro empresas. 
Tabela 1. Evolução da participação do número de empresas financiadas pelo Cartão BNDES no total de empresas no Brasil por setor - 2007-2012 (em \%)

\begin{tabular}{ccccccc}
\hline Setor & 2007 & 2008 & 2009 & 2010 & 2011 & 2012 \\
\hline Agropecuária & 0,4 & 0,5 & 1,1 & 1,7 & 2,5 & 2,7 \\
Indústria & 1,4 & 2,0 & 4,6 & 6,8 & 9,1 & 10,1 \\
Comércio & 0,8 & 1,2 & 3,1 & 5,0 & 7,3 & 8,5 \\
Serviços & 0,8 & 1,1 & 2,6 & 4,0 & 5,6 & 6,3 \\
Total & 0,8 & 1,1 & 2,8 & 4,4 & 6,3 & 7,2 \\
\hline
\end{tabular}

Fonte: BNDES (2015)

Dessa forma, quando se compara as operações do cartão BNDES nos anos 2004 e 2014, observa-se que em 2014 houve uma desconcentração da utilização desse cartão em relação as regiões brasileiras, outras localidades que até então não apresentavam uma alta utilização, passam a ter números representativos (Barbosa et al, 2019).

Uma das razões dessa desconcentração, foi a política econômica adotada em meados de 2008 e 2009, devido à crise econômica internacional. O BNDES foi um dos instrumentos adotados pelo governo para aumentar a oferta de crédito, já que neste momento houve uma restrição do sistema financeiro privado (Barbosa et al, 2019).

A partir de 2009 houve uma popularização do cartão BNDES, muito em parte ao programa BNDES de sustentabilidade de investimento (PSI), que focava em investimentos nos setores de logística, energético e social urbano, setores de extrema importância para a continuidade da atividade econômica, além de alterarem condições fixas como o aumento do limite de $\mathrm{R} \$ 500.000$ do cartão, para $\mathrm{R} \$ 1.000 .000$, incentivando essa procura por crédito público, enquanto que a crise financeira internacional restringia a oferta de crédito privado. As atividades do PSI inicialmente seriam executadas apenas no ano de 2009, mas acabaram se perdurando até 2018, sendo 2013 o último ano em que foi bastante utilizado (BNDES,2009).

Outras explicações, de acordo com Oliva e Zendron (2010) para essa desconcentração, foi a política econômica adotada em meados de 2008 e 2009, devido à crise econômica internacional. O BNDES foi um dos instrumentos adotados pelo governo para aumentar a oferta de crédito, já que neste momento houve uma restrição do sistema financeiro privado. A partir de 2009 houve uma popularização do cartão BNDES, muito em parte ao programa BNDES de sustentabilidade de investimento (PSI), que focava em investimentos nos setores de logística, energético e social urbano, setores de extrema importância para a continuidade da atividade econômica, além de alterarem condições fixas como o aumento do limite de $\mathrm{R} \$ 500.000$ do cartão, para $\mathrm{R} \$ 1.000 .000$, incentivando essa procura por crédito público, enquanto que a crise financeira internacional restringia a oferta de crédito privado. As atividades do PSI inicialmente seriam executadas apenas no ano de 2009, mas acabaram se perdurando até 2018, sendo 2013 o último ano em que foi bastante utilizado (BNDES, 2009). 
Embora essas operações ainda sejam altamente concentradas nas regiões Sudeste e Sul no ano de 2014, haja vista que os setores da indústria e de serviços no Brasil se concentram mais nessas duas regiões de acordo com o IBGE (2004b, 2012c, 2012b, 2013,2014a) sendo que a indústria, segundo informações da tabela 1, foi a que teve maior participação percentual no total de recursos do cartão BNDES entre os anos 2007 a 2012, a queda da concentração nas regiões Sudeste e Sul observada em 2014 também pode ser explicada como resultado da elevação demanda pelos recursos do cartão BNDES que ocorreu nas regiões Norte, Centro-Oeste e Nordeste em virtude de alguns fatores, tais quais a disseminação de informações sobre este produto, por meio de políticas de marketing e novos canais de informação do BNDES, predominância da produção agrícola no Centro Oeste em 2014 de acordo com IBGE (2012a, 2004a), que aliado à evolução da participação percentual das empresas do setor da agropecuária financiadas pelo cartão BNDES, conforme a tabela 1, acarretou em aumento de recursos destinados ao Centro-Oeste e também o aumento da participação da região nordeste, norte e centro-oeste no setor de serviços, de acordo com IBGE (2012b), que também teve aumento de participação do número de empresas financiadas pelo cartão BNDES entre 2007 e 2012 conforme as informações da tabela 1 também ajuda a explicar queda de concentração nas regiões Sudeste e Sul na curva de Lorenz quando se inclui as regiões centro-oeste, nordeste e norte quando se compara os anos de 2004 e 2014.

\section{Conclusão}

A partir dos resultados do quociente locacional, foi possível verificar que existe uma diferença na utilização do cartão BNDES nas unidades federativas do país durante o intervalo analisado, já que em 2004 os setores que apresentaram predominância nas regiões brasileiras, em sua grande maioria não foram as mesmas de 2014, apontando para uma outra configuração no uso do cartão. Nas regiões Norte e Nordeste, que até então, tinham unidades federativas que não usavam muito o cartão, mas que em 2014 apresentam uma evolução nesse uso, além de apresentarem essa homogeneização em volta de determinado setor, mostrando que os MPMES, dessa região acabam necessitando de maior financiamento nesse setor.

A região Sudeste não se comportou de forma diferente na questão do uso o do cartão BNDES. Desde 2004, a região foi uma das primeiras a utilizar este produto do BNDES, obtendo uma configuração de diversificação nos números de setores que tiveram alguma operação efetuada. Concentrando os grandes centros econômicos do país, essa região acaba por dominar o uso do cartão, em grande parte devido à quantidade de MPMEs, fazendo com que a região tenha um alto número de operações contratadas. Na análise setorial se percebeu a evolução do cartão, pois em 2004, não existia nenhum setor absoluto na região, que demostrasse especialização nos quatro estados, todavia, a configuração já se altera em 2014, com a região reduzindo a sua participação no valor total das operações contratadas, passando a região a ter uma especialização em diversos setores, expondo uma maior utilização do cartão e no contexto de especialização, mostrando os setores que sentiram a necessidade de investir na sua estrutura produtiva 
A partir da análise dos dados, na região Sul desde 2004, o setor C, da indústria de transformação já mostrava uma especialização em todos os estados, o que acabou também ocorrendo em 2014, com acréscimo ainda de outro setor, o $\mathrm{H}$, referente a transporte, armazenagem e correio. Comparando com as outras regiões, o Sul nos dois anos se mostrou uma das regiões que mais dispendia em operações do cartão BNDES, ficando atrás apenas da região Sudeste, além de também apresenta um alto número de MPMEs frente as outras regiões do país.

A região Nordeste foi uma das que apresentou maior crescimento na participação do uso do cartão BNDES. Em 2014, os números saltam, e a participação nordestina nas operações contratadas mais que dobram, sendo que todos os estados da região se especializaram no setor $G$, responsável pelo comércio, reparação de veículos automotores e motocicletas.

No Centro-Oeste, apesar do aumento no valor das operações, a participação da região no valor total continuou o mesmo, de mostrando que a representatividade da região na utilização do cartão BNDES, se manteve no mesmo patamar em 2014. Em relação ao comportamento setorial, se verificou que houve uma alteração na especialização, enquanto que em 2004 o setor L-N, responsável pelas atividades imobiliária, administrativas e profissionais, apresentava especialização em todos os estados da região. Em 2014 as atividades A, responsável pela agricultura, pecuária, produção florestal, pesca e aquicultura, e a atividade $G$, responsável pelo comércio, reparação de veículos automotores e motocicletas, foram as que apresentaram especialização em todos os estados dessa região.

A região Norte em relação a utilização do cartão BNDES, houve uma mudança no comportamento da região, já que em 2004 o produto em si não era nem utilizado em todos os estados da região. Acre e Roraima não apresentaram nenhuma operação do produto no nesse ano, o que já muda em 2014, ano no qual todos os estados apresentaram operações contratadas no cartão. Em relação ao comportamento setorial, verifica-se que ocorreu uma alteração, já que a região anteriormente apresentavam uma diversificação de setores com especialização entre os estados, e em 2014, o setor F referente a construção e $G$ referente a comércio, reparação de veículos automotores e motocicletas, mostrou especialização em todos os estados da região, demonstrando que em toda a região, esses setores demandaram investimentos.

Quando analisamos todas as regiões juntas, verifica-se as discrepâncias da utilização do cartão BNDES nas unidades federativas no ano de 2004, e a sua evolução para o ano de 2014. Foi possível perceber que em um primeiro momento, as operações do cartão se concentraram nos grandes centros econômicos, como a região Sudeste e Sul, estando as demais regiões em uma menor representatividade, algo que muda em 2014, com a maior participação das regiões Norte e Nordeste, permitindo que as MPMEs dessas regiões obtivessem a oportunidade de utilizar esse produto para financiar a sua produção. Ainda que de certa maneira a região Sudeste ainda continua concentrando boa parte das operações, é possível visualizar que houve uma melhora na utilização do cartão no que concerne a concentração, auxiliando no financiamento das MPMEs de não só uma determinada região, mas de todo o Brasil. 


\section{REFERÊNCIAS}

AUDRETSCH, D, B.; FELDMAN, M, P. Innovation in Cities: Science-based Diversity, Specialization and Localized Competition. European Economic Review, Amsterdam, n.2, v.43, p.409-429, fev. 1999.

ALMEIDA, E. O papel de bancos públicos para o desenvolvimento econômico e social. Brasília: Instituto de Pesquisa Econômica Aplicada, 2017. 60 p. (Texto para Discussão 1604). Disponível em: <http://repositorio.ipea.gov.br/handle/11058/7935>. Acesso em: 30 nov. 2017.

BARBOZA, R. M.; FURTADO, M; GABRIELLI, H. A atuação histórica do BNDES: o que os dados têm a nos dizer? Rio de Janeiro: BNDES, 2018. 27 p. (Textos para Discussão, n. 123). Disponível em:

https://web.bndes.gov.br/bib/jspui/bitstream/1408/14620/1/TD_123-

AtuacaoHistorica_P_BD.pdf. Acesso em: 30 vov.2017.

BARBOSA, $R$, M. et al. O BNDES e as micro, pequenas e médias empresas. Rio de Janeiro: BNDES, 2019. 48 p. (Textos para Discussão, n. 146). Disponível em: https://web.bndes.gov.br/bib/jspui/bitstream/1408/18702/3/TD_146_WEB.pdf. Acesso em: 10 ago. 2020.

BARROS, A, R. Desigualdades Regionais no Brasil. Rio de Janeiro: Elsevier, 2011. 336 p.

BECK, T.; DEMIRGUC-KUNT, A.; LEVINE, R. SMEs, Growth, and Poverty: CrossCountry Evidence. Journal Of Economic Growth, Berlim, v. 10, n. 3, p.199-229, set. 2005.

BRASIL. Decreto n. 4.418, de 11 de out. de 2002. Dispõe sobre aprovação do novo Estatuto Social da empresa pública Banco Nacional de Desenvolvimento Econômico e Social - BNDES. DOU: Diário Oficial da União. Brasília, v. 48, p. 20-25, out. 2004.

BANCO NACIONAL DE DESENVOLVIMENTO ECONÔMICO E SOCIAL - BNDES. Relatório Anual Bndes, 2005. Rio de Janeiro: Banco Nacional de Desenvolvimento Econômico e Social, 2006. 201 p.

BANCO NACIONAL DE DESENVOLVIMENTO ECONÔMICO E SOCIAL - BNDES. Desembolso do BNDES cresceram 14\% e atingiram R\$ 40 bilhões em 2004, 2005. Disponível 
em:<https://www.bndes.gov.br/wps/portal/site/home/imprensa/noticias/conteudo/2 0050113_not007_05>. Acesso em: 11, agosto de 2020.

BANCO NACIONAL DE DESENVOLVIMENTO ECONÔMICO E SOCIAL - BNDES. BNDES encerra 2009 com desembolso recorde de R\$137,3 bilhões. 2009. Disponível em: https://www.bndes.gov.br/wps/portal/site/home/imprensa/noticias/conteudo/20091 229_desemp_2009. Acesso em: 12 ago. 2020.

BANCO NACIONAL DE DESENVOLVIMENTO ECONÔMICO E SOCIAL - BNDES. RELATÓRIO de Efetividade 2007-2014: a contribuição do BNDES para o desenvolvimento nacional. Rio de Janeiro: Banco Nacional de Desenvolvimento Econômico e Social, 2015.132 p.

CROCCO, M, A. et al. Metodologia de identificação de aglomerações produtivas locais. Nova economia, Belo Horizonte, n.2, v.16, p.211-241, Maio./Ago. 2006.

DUTRA, L. D. et al. Desigualdade na oferta de crédito regional a pessoas jurídicas: uma análise em painel para o período 2000-2011. Economia e Sociedade, Campinas, v. 24, n. 3, p. 681-708, dez. 2015.

FERRAZ, João Carlos; MARQUES, Felipe Silveira; ALVES JÚNIOR, Antônio José. A contribuição do BNDES para a política industrial brasileira 2003-2014. In: Toni, J (Org.). Dez anos de política industrial: balanço e perspectivas 2004 - 2014. Brasília. 2015. p. 61-91.

GALINARI, R.et al. O apoio do BNDES a micro, pequenas e médias empresas por meio de redes empresariais: experiências recentes e perspectivas. BNDES Setorial, Rio de Janeiro, n.43, p.81-118, mar, 2016.

GUERRA, O.; TEIXEIRA, F. A sobrevivência das pequenas empresas no desenvolvimento capitalista. Revista de Economia Política, Rio de Janeiro, v. 30, n. 1, p.124-139, mar. 2010.

HADDAD, P, R. Medidas de localização e de especialização. In: HADDAD, P, R. et al. (Org.). Economia regional: teorias e métodos de análise. Fortaleza: BNB-ETENE, 1989, p. 7-32.

HIRT, C. Estado, Capital e políticas governamentais: o lugar e papel do BNDES no desenvolvimento brasileiro entre os anos de 2003 e 2014. In: XVIII ENCONTRO NACIONAL DA ASSOCIAÇÃO NACIONAL DE PÓS-GRADUAÇÃO E PESQUISA EM PLANEJAMENTO URBANO E REGIONAL, 2019, Natal, RN. Anais... Natal: EDUFRN, 2019. $P$ 57-80. 
Instituto Brasileiro de Geografia e Estatística - IBGE. Estimativas de População. Disponível em: https://sidra.ibge.gov.br/tabela/6579. Acesso em: 30 abr.2019.

. Cadastro Central de Empresas. Disponível em:

https://sidra.ibge.gov.br/tabela/6450. Acesso em: 30 abr.2019.

. Levantamento sistemático da produção agrícola : pesquisa mensal de previsão e acompanhamento das safras agrícolas no ano civil. Rio de Janeiro, $2004 a$. Disponível em: https://biblioteca.ibge.gov.br/index.php/bibliotecacatalogo?view=detalhes\&id=76. Acesso em: 14 ago.2020Instituto Brasileiro de Geografia e Estatística - IBGE.

. Levantamento sistemático da produção agrícola : pesquisa mensal de previsão e acompanhamento das safras agrícolas no ano civil. Rio de Janeiro, 2012a. Disponível em: https://biblioteca.ibge.gov.br/index.php/bibliotecacatalogo?view=detalhes\&id=76. Acesso em: 14 ago.2020.

. Pesquisa anual de serviços. Rio de Janeiro, 2012b. Disponível em: https://www.ibge.gov.br/estatisticas/economicas/servicos/9028-pesquisa-anual-deservicos. html?edicao $=17104 \& \mathrm{t}=$ downloads.

. Pesquisa anual de serviços. Rio de Janeiro, 2014a. Disponível em: https://biblioteca.ibge.gov.br/visualizacao/periodicos/150/pas_2014_v16.pdf. Acesso em: 14 ago.2020.

. Anuário Estatístico do Brasil. Rio de Janeiro, 2004b. Disponível em: https://biblioteca.ibge.gov.br/visualizacao/periodicos/20/aeb_2004.pdf. Acesso em: 14 ago.2020.

Anuário Estatístico do Brasil. Rio de Janeiro, 2014c. Disponível em: https://biblioteca.ibge.gov.br/visualizacao/periodicos/20/aeb_2014.pdf. Acesso em: 14 ago.2020.

.Contas regionais do Brasil : 2004 / IBGE, Coordenação de Contas Nacionais. Rio de Janeiro: IBGE, 2006. 78 p. Disponível em: https://biblioteca.ibge.gov.br/index.php/bibliotecacatalogo?view=detalhes\&id=232361. Acesso em: 14 jun.2019.

.Contas regionais do Brasil: 2010-2014. Rio de Janeiro: IBGE, 2016. 85p. https://biblioteca.ibge.gov.br/index.php/bibliotecacatalogo?view=detalhes\&id=298881. Acesso em: 14 jun.2019. 
. Estatísticas do Cadastro Central de Empresas. Rio de Janeiro: IBGE, 2006. 262p. Disponível em: https://biblioteca.ibge.gov.br/index.php/bibliotecacatalogo?view=detalhes\&id=231982. Acesso em: 14 jun.2019.

LIMA, J. F. et al. O uso das terras no sul do Brasil: uma análise a partir de indicadores de localização. Revista de Economia e Sociologia Rural, Brasília, v.44, n.4, p.677694, out./dez. 2006.

MONTEIRO NETO, A. Desigualdades regionais no Brasil: notas sobre o padrão de intervenção do Estado nos anos 2000-2010. In: GUIMARÃES, P, F.; AGUIAR, R, A.; LASTRES, H, M, M.; Silva, $M, M$ (Org.). Um olhar territorial para o desenvolvimento: Nordeste. Rio de Janeiro : Banco Nacional de Desenvolvimento Econômico e Social, 2014. p.176-205

NOGUEIRA, M, O.; ZUCOLOTO, G. Um Pirilampo no Porão: um pouco de luz nos dilemas da produtividade das pequenas empresas e da informalidade no Brasil. Brasília: IPEA, 2017. 308 p.

OLIVA, R.; ZENDRON, P. Políticas governamentais pró-investimento e o papel do BNDES. In: ALÉM, A, C; GIAMBIAGI, F (org.). O BNDES em um Brasil em transição. Rio de Janeiro: Bndes, 2010. p. 65-86

PAULA, $G, M$. Inclusão financeira de pequenas e médias empresas no Brasil. Santiago: Cepal, 2017. 91 p.

PEZZI, S, L. Acesso ao crédito por parte das micro e pequenas empresas brasileiras no período pós-plano real. 2005. 133 p. Dissertação (Mestrado em Economia do Desenvolvimento) - Faculdade de Administração, Contabilidade e Economia, Pontifícia Universidade Católica do Rio Grande do Sul, Porto Alegre, 2005.

RECEITA FEDERAL DO BRASIL- RFB. Classificação Nacional de Atividades Econômicas CNAE. Disponível em: $<$ https://cnae.ibge.gov.br/?view=estrutura\&tipo=cnae\&versao_classe=7.0.0\&versao subclasse $=9.1 .0>$. Acesso em: 10 set. 2020

SCHUMPETER, J. O Fenômeno Fundamental do Desenvolvimento Econômico. São Paulo: Nova Cultural, 1985. 228 p.

SOUZA, N, J. Desenvolvimento na visão shumpeteriana.

In:____ Desenvolvimento Econômico. São Paulo: Atlas, 1997. p 27-42. 
STIGLITZ, J, E.; WEISS, A. Credit Rationing in Markets with Imperfect Information. The American Economic Review, Pittsburgh, v.71, n.3, p. 393-410, jun. 1981.

TONI, J. Introdução. In: (Ed.). Dez anos de Política Industrial: balanço e perspectivas. Brasília: ABDI, 2015. p 7-10.

ZICA, R, M, F.; MARTINS, H, C.; CHAVES, A, F, B. Dificuldades e perspectivas de acesso ao sistema financeiro nacional pelas micro e pequenas empresas. São Paulo: Egepe Mackenzie, 2008. 128 p.

SUZIGAN, W. et al. Coeficientes de Gini locacionais-GL: aplicação à indústria de calçados do Estado de São Paulo. Nova Economia, Belo Horizonte, v.13, n.2, p.39-6o, Jul./Dez, 2009.

Mauro Thury de Vieira Sá. Doutor em Ciência Econômica pelo Instituto de Economia da Unicamp. Filiação institucional: Departamento de Economia e Análise da Faculdade de Estudos Sociais da Universidade Federal do Amazonas (DEA/ FES/ UFAM). Cargo: Professor Associado IV. Endereço para correspondência: Av. Gen. Rodrigo Octávio, 6.200, Pavilhão Administrativo da Faculdade de Estudos Sociais (FES), piso superior, sala 11, Setor Norte, Campus Universitário Sen. Arthur Virgílio Filho, bairro Coroado I; CEP 69080-900, ManausAM.E-mail:mtvsa@ufam.edu.br.

Diogo Del Fiori. Doutor em Economia Aplicada. Filiação institucional: Departamento de Economia e Análise da Faculdade de Estudos Sociais da Universidade Federal do Amazonas (DEA/ FES/ UFAM). Cargo: Professor Adjunto Classe C nível I. Endereço para correspondência: Av. Gen. Rodrigo Octávio, 6.200, Pavilhão Administrativo da Faculdade de Estudos Sociais (FES), piso superior, sala 11, Setor Norte, Campus Universitário Sen. Arthur Virgílio Filho, bairro Coroado I, CEP 69080-900, Manaus-AM. E-mail: diogofiori@ufam.edu.br.

Petrick Kristofer Andrade da Costa. Graduado em Ciências Econômicas. Filiação institucional: Associação Voluntários para o Serviço Internacional - Brasil. Cargo: Assistente de Operações. Endereço para correspondência: SRTVS Qd 701 Bloco O Ed. Multiempresarial Sala 531, Asa Sul, CEP 70340000, Brasília-DF. E-mail: petrick.pk@gmail.com

Como citar: DE VIEIRA SÁ, Mauro Thury; FIORI, Diogo Del; ANDRADE DA COSTA, Petrick Kristofer. Análise da Utilização do Cartão BNDES nas Regiões Brasileiras no Período 20042014. Redes (St. Cruz Sul, Online), Santa Cruz do Sul, v. 25, p. 2494-2523, dez. 2020. ISSN 1982-6745. doi:https://doi.org/10.17058/redes.v25i0.15042. 


\section{CONTRIBUIÇÃO DE CADA AUTOR}

a. Fundamentação teórico-conceitual e problematização: Todos os autores

b. Pesquisa de dados e análise estatística: Mauro Thury de Vieira Sá

c. Elaboração de figuras e tabelas: Petrick Kristofer Andrade da Costa

d. Fotos: Não se aplica ao artigo

e. Elaboração e redação do texto: Todos os autores

f. Seleção das referências bibliográficas: Petrick Kristofer Andrade da Costa

Fontes de financiamento: não se aplica. 